\title{
Measuring the well-being of health care professionals in the Punjab: a psychometric evaluation of the Warwick-Edinburgh Mental Well-being Scale in a Pakistani population
}

Ahmed Waqas, Waqas Ahmad, Mark Haddad, Frances M Taggart, Zerwah Muhammad, Muhammad Hamza HB Bukhari, Shahzad Ahmed Sami, Sayyeda Mehak Batool, Fiza Najeeb, Ayesha Hanif, Zehra Ali Rizvi, Sumbul Ejaz

Background: There is growing awareness of the public health importance of the mental well-being of population in general. This study was carried out to examine the wellbeing of Pakistani healthcare professionals, and to evaluate the psychometric properties of Warwick-Edinburgh Mental Well-being Scale in in this population. The well-being of health professionals is likely to influence their care delivery. Methods: A cross-sectional survey was carried out from June, 2013 to December, 2014 among 1271 Pakistani health personnel (HCPs) belonging to seven different cities of Punjab province, Pakistan, to examine the acceptability, internal consistency, test-retest reliability and the content and construct validity of the English version of the Warwick-Edinburgh Mental Well-being Scale in a Pakistani population sample. All data were analyzed in SPSS v.21. Results: Our analysis demonstrated a unidimensional construct, a high internal consistency $(0.89)$ and test-retest reliability, good convergent validity and easy readability of WEMBS among Pakistani HCPS. The mean on WEMWBS score was 48.1 (9.4) which is lower than general population sample in other nations. Male healthcare professionals scored significantly higher on WEMWBS than their female counterparts $(P<.05)$, and older respondents had higher scores. Conclusion: The WEMBS appears feasible and acceptable for use in the Pakistani healthcare professionals, and findings from this study indicate its validity and internal consistency. The well-being scores of the health professional respondents were lower than those identified in general population surveys in the UK. 
1 Measuring the well-being of health care professionals in the Punjab: a psychometric

2 evaluation of the Warwick-Edinburgh Mental Well-being Scale in a Pakistani population

4 Authors: Ahmed Waqas ${ }^{1}$, Waqas Ahmad ${ }^{1}$, Mark Haddad ${ }^{2}$, Frances Taggart ${ }^{3}$, Zerwah

5 Muhammad $^{1}$, Muhammad Hamza Bukhari ${ }^{1}$, Shahzad Ahmed Sami ${ }^{1}$, Sayyeda Mehak Batool ${ }^{1}$,

6 Fiza Najeeb ${ }^{1}$, Ayesha Hanif ${ }^{1}$, Zehra Ali Rizvi $^{1}$, Sumbul Ejaz ${ }^{1}$

Affiliation: ${ }^{1}$ CMH Lahore Medical College and Institute of Dentistry, Lahore Cantt, Pakistan

$9{ }^{2}$ Centre for Mental Health Research, School of Health Sciences, City University London,

10 Northampton Square, London EC1V 0HB, United Kingdom

$11{ }^{3}$ Statistics and Epidemiology Unit, Division of Health Sciences, University of Warwick Medical

12 School, Coventry, United Kingdom

Corresponding author: Ahmed Waqas

Funding support: none

Conflict of interest: none

Manuscript word count: 3603 (Excluding references)

Abstract word count: 237

Keywords: mental fatigue, burnout, Warwick-Edinburgh Mental Well-being Scale, WEMWBS, health professionals, mental health 


\section{Abstract}

\section{Background:}

There is growing awareness of the public health importance of mental well-being both in the general population and in specific groups. The well-being of health professionals is likely to influence the quality of the care they deliver. This study was carried out to examine the wellbeing of Pakistani healthcare professionals, and to evaluate the psychometric performance of the Warwick-Edinburgh Mental Well-being Scale (WEMWBS) in this population.

Methods:

A cross-sectional survey was carried out from June, 2013 to December, 2014 among 1271

Pakistani health care providers (HCPs) working in seven different cities in Punjab province,

Pakistan, to examine the acceptability, internal consistency, test-retest reliability and content and construct validity of the English version of the WEMWBS in a Pakistani population sample. All data were analyzed in SPSS v. 21.

Results:

Our analysis demonstrated unidimensional construct validity, high internal consistency $(0.89)$ and test-retest reliability, good validity and easy readability of WEMWBS in our sample of Pakistani HCPs. The mean WEMWBS score was 48.1 (SD 9.4), which is lower than in the general population in other countries. Male HCPs scored significantly higher on the WEMWBS than their female counterparts $(\mathrm{P}<0.05)$, and older respondents had higher scores.

\section{Conclusion:}

44 The WEMWBS appears acceptable for use in Pakistani HCPs, and findings from this study verify its validity and internal consistency for this population sample. Our respondents had lower well-being scores than those reported in general population surveys in the UK. 


\section{Introduction}

Subjective or psychological well-being is increasingly recognized as a crucial aspect of overall

health that highlights the importance of positive mental health. It relates to the classic World

Health Organization (WHO) definition of health as more than just the absence of disease:

"Health is a state of complete physical, mental and social well-being and not merely the absence

of disease or infirmity" [1]. The importance of mental health for overall well-being is emphasized in international policy as the "foundation for well-being and effective functioning for both the individual and the community (which) allows individuals to realise their abilities, cope with the normal stresses of life, work productively and fruitfully, and make a contribution to their community" $[2,3]$. of life [3] and its measurement has been embedded within this construct. For example, measures of quality of life and of health-related quality of life commonly incorporate questions concerning positive and negative affect $[4,5]$ as well as life satisfaction and considerations of fulfilment and purpose, as for instance in the triennial European Quality of Life Survey [6]. However, over the past two decades, interest in measuring subjective well-being has expanded, with the emergence of evidence that it can be measured in ways that are valid and reliable [3]. There is now widespread acknowledgement that focusing on the measurement of subjective well-being is an previous emphasis on deficits, problems and symptoms. This is evident within psychiatric research, mental health policy and clinical practice [8], where the concepts of recovery and the 
use of well-being measures are increasing [9]. Within the broader context of public health and policy, the current focus on positive elements relates to an acknowledgment that promoting wellbeing and independence is essential to prevent ill health, which is of particular relevance in light of the growing burden of long-term conditions [10].

Within health services, staff well-being is recognized to be relevant to the quality and safety of health care delivery [11] as well as to efforts and expenditures to recruit and retain clinical staff [12]. The health care sector ranks high in studies of important potential causes of work stress [13], with health professionals (in particular nurses) among those who report the highest 3-year average rates of work-related stress, depression or anxiety [14]. An extensive literature has explored stress among health professionals, using measures of psychological distress as well as more conceptually elaborate and specific tools such as burnout instruments [15]. Stressors that may be evident in health professionals' work environment include long and unsocial working hours, prolonged and cumulative involvement with seriously ill patients and their relatives, and exposure to organizational conflicts. Even during their training, health care providers (HCPs) are exposed to a plethora of academic, psychosocial and health-related stressors [16]. Medical students and junior doctors have been reported to be at particular risk, but estimates of prevalence vary widely from $18 \%$ to $82 \%$ [17].

Studies among health care professionals in Pakistan have reported a high prevalence of anxiety, depression, high stress levels and burnout, highlighting the need to address the issues of poor job satisfaction, sleep deprivation due to shift patterns, patient overload, authoritarian work relationships and limited peer and social support [18-20]. In line with the growing emphasis on measures of positive health rather than a focus on deficits and problems, we believed it would be useful to measure the subjective mental well-being of HPCs in Pakistan. The most widely known 
93

94

95

96

97

98

99

100

101

102

103

104

105

106

107

108

109

110

111

112

113

114

115

measure of mental well-being in the UK is the Warwick Edinburgh Mental Well-being Scale

(WEMWBS), developed by the Universities of Warwick and Edinburgh and funded by NHS

Scotland.

The current study was devised to examine the psychometric characteristics of the

WEMWBS instrument among English-speaking Pakistani health professionals. This information is useful because i) few psychological and psychiatric rating scales have been cross-culturally validated for use in the Pakistani population [21], and ii) the mental health scales that have been evaluated for use in this population are largely measures of symptoms of mental disorders rather than of positive mental health.

\section{Materials and methods}

\section{Questionnaire and instrument}

The questionnaire consisted of two sections. The first section recorded information related to respondents' demographics and profession, and the second section assessed mental well-being levels with the WEMWBS.

The WEMWBS was developed and extensively validated in the UK general population [22]. This self-administered questionnaire comprises 14 positively-worded items that assess eudaimonic (focused on psychological functioning and a sense of meaning and purpose in life) and hedonic (focused on happiness, contentment and life satisfaction) constructs of mental wellbeing. Responses are recorded on a 5-point Likert scale ranging from "none of the time" (score 1) to "all the time" (score 5). For analysis, the total score is obtained by summing the scores for all of the items. There is no reverse coding. Higher scores indicate greater well-being. The lowest possible score is 14 (low well-being) and the highest possible score is 70 (high well-being). 
117 properties, and is feasible, reliable, and sensitive to change. Cronbach's alpha for the scale lies

118 between 0.87 and 0.91 , and 1 -week test-retest reliability studies reported very good correlation

119 with $\mathrm{r}=0.83$. Validation studies have been done in different population samples in the UK, such

120 as Scottish undergraduate and postgraduate students, the general population [22], English and

121 Scottish teenagers [24], and Pakistani and Chinese ethnic minorities [25]. The WEMWBS has

122 also demonstrated high internal consistency, good content and face validity, normal response

123 distribution and no floor or ceiling effects in previous validation studies [22,24,25].

\section{Pilot survey}

126 A pilot study was conducted in which a convenience sample of 50 health care professionals

127 including doctors, nurses and dentists in the Combined Military Hospitals in Lahore completed

128 and commented on the WEMWBS to tell us whether the original English-language version could

129 be easily understood and completed. Positive feedback from these participants indicated that the

130 WEMWBS was very easy to understand. We therefore felt it was not necessary to translate this

131 instrument into Urdu (the participants' first language).

\section{Sample size calculation}

134 Sample size is generally calculated on the basis of variability in the sample and the expected

135 effect size. Usually both of these are unknown before starting the study, and numbers are

136 estimated from previous studies, or sometimes with "rules of thumb" based on previous

137 experience. Most studies of questionnaires validation in social sciences use 5 to 10 respondents

138 per questionnaire item for factor analysis. Factor analyses are subject to the strength of 
139

140

141

142

143

144

145

146

147

148

149

150

151

152

153

154

155

156

157

158

159

160

161 60

communalities and factor loading, so these statistical tests should instead be based on large samples for reliable results [26]. Comrey and Lee recommend at least 500 cases, and according to their rating scale a sample size of 1000 or more is considered excellent for factor analysis studies [27]. We therefore aimed for a sample size of at least 1000 HCPs.

\section{Procedure}

This cross-sectional survey was carried out from June, 2013 to December, 2014. The study sample consisted of doctors, nurses, physiotherapists, pharmacists and dentists practicing either in hospital-based or private settings in various cities of the province of Punjab, Pakistan. Seven districts - Lahore, Faisalabad, Gujrat, Multan, Rawalpindi, Islamabad and Sheikhupura - were included in the survey for a study sample representative of the Punjabi population. However, due to resource limitations, we could not obtain a systematic random sample. Data were therefore collected with a convenience sampling approach. Sixteen medical students (currently in their final year of the MBBS degree program) approached HCPs in all available clinical settings in the Punjab province. An independent sample of $50 \mathrm{HCPs}$ from $\mathrm{CMH}$ Lahore participated in the testretest assessment of WEMWBS and completed the questionnaire twice, with a test-retest interval of 7 days.

6 Ethical approval was obtained from the Ethical Review Committee of CMH Lahore Medical College, Lahore Cantt, Pakistan. Written informed consent was provided by all the study participants. The respondents were ensured anonymity and informed that only group-level findings would be reported.

61 Statistical analysis 
162 All data were analyzed with SPSS v. 21 (IBM Chicago, IL, USA). Frequencies and descriptive

163 statistics were calculated for demographic variables and total scores on the WEMWBS.

164 Histograms and quantile-quantile (Q-Q) plots were visualized to check the assumption of

165 normality for WEMWBS scores, and we also looked for floor and ceiling effects in the response

166 distribution. Factor analysis with principal component analysis (PCA) and quartimax rotation

167 were done to evaluate the construct validity of the WEMWBS. Prior to PCA, its suitability was

168 assessed with the following criteria: correlation coefficient $>0.3$ for all variables, an overall

169 Kaiser-Meyer-Olkin (KMO) measure greater than 0.6, and a statistically significant Barlett's test

170 of sphericity $(\mathrm{P}<0.05)$. The number of components to retain was determined with Cartell's scree

171 plot, eigenvalues $>1$, interpretability criterion, the amount of variance explained and reliability

172 analysis.

Only those statements were included that had a factor loading $>0.3$. Cronbach's alpha

coefficient was calculated to estimate the internal consistency of WEMWBS in our study sample,

175

176 and a value of 0.70 to 0.9 was considered acceptable [28]. Item-total correlations were calculated with Pearson's product moment correlation coefficient, and values that were substantial but not excessive (greater than or equal to 0.2 and less than 0.8 ) were sought [28]. Test-retest reliability was evaluated as the intraclass correlation coefficient with a two-factor mixed effects model and type consistency.

Floor and ceiling effects were sought by examining response patterns for each of the factors derived from factor analysis. Scores were graphed as a histogram, and the distribution of scores was inspected; the percentage of individuals with the lowest and highest possible score in each of the factors was recorded, and values greater than $20 \%$ were considered as floor and ceiling effects. 

with independent sample t-tests. Although focus groups have been used to evaluate participants' comprehension and ease of completion [25], previous studies of the WEMBWS have not examined its readability. Therefore we used the Flesch Reading Ease score and Flesch-Kincaid Grade Level function to determine the readability of the questionnaire [29].

\section{Results}

\section{$\underline{\text { Response rate }}$}

193 The total response rate was $90.7 \%(1271 / 1400)$.

\section{$\underline{\text { Demographics }}$}

1271 individuals responded to the questionnaire. Respondent characteristics are summarized in

Table 1. Participants' ages ranged between 20 and 68 years, with a mean age (SD) of 31.8 (9.4) years. Mean age was greater for men [34.1 (10.3) years] than women [30.0 (8.1) years]. Most of the respondents were doctors $(n=840,66 \%)$ or nurses $(n=218,17.2 \%)$, female $(n=720,57 \%)$, and practicing in Lahore $(\mathrm{n}=70 \%)$. profession: nurses were almost all (97\%) female, whereas among doctors and dentists there was a nearly equal gender representation. 42 of the pharmacists were male (79\%), as were $16(64 \%)$ of the physiotherapists. There were no significant age differences between the professional groups except for dentists in the sample, whose mean age was younger than for the other professions [28.5 (6.6) years; $\mathrm{P}<0.001]$. 


\section{Descriptive statistics and floor or ceiling effects}

209 Mean (SD) score on the WEMBWS was 48.1 (9.4), and median score was 48. Analysis of item

210 response frequencies showed little evidence of highly skewed distributions, with a mild

211 skewness of $-0.31(0.07)$ and a kurtosis of $0.42(0.14)$. Visual inspection of the histograms and

212 Q-Q plots did not reveal any significant deviation of response distribution from normality. All

213 response categories were used by at least one person for all the scale items. Mean values for

214 individual items ranged from 2.88 (1.1) for "I've had energy to spare" to 3.74 (0.99) for "I've

215 been feeling confident" (Table 2). A histogram of the distribution of mean scores is shown in

216 Figure 1. Based on these results, we conclude that the WEMWBS is valid for the Pakistani

217 population is free from any floor or ceiling effects.

218 As in the UK validation study [22] mean WEMWBS scores were significantly higher for 219 men (49.16) than for women (47.30) $(\mathrm{t}=3.486, \mathrm{df}=1269, \mathrm{P}=0.001)$ (Table 1).

220 There were differences in well-being scores between professional groups. Doctors' and 221 nurses' mean WEMWBS scores were lower than those for the other professional groups. The 222 difference between WEMWBS score for doctors and nurses combined, compared to the other 223 professional groups combined, was statistically significant $(\mathrm{P}=0.002$, mean difference 2.22 , $224 \mathrm{t}=-3.14, \mathrm{df}=1269)$. A difference in well-being score was evident across age groups, with 225 participants aged 30 years and older scoring higher on the WEMWBS than younger participants $226(\mathrm{P}=0.013$, mean difference $1.33, \mathrm{t}=2.48, \mathrm{df}=1269)$. Items $2,10,11$ and 12 received the most positive ratings by both men and women, whereas items 3, 4 and 5 received the least positive ratings by participants of both genders. 
231 The WEMWBS responses were subjected to PCA, and the correlation matrix showed that all

232 variables had at least one correlation coefficient greater than 0.3 . The overall KMO measure was

233 0.83, with individual $\mathrm{KMO}$ measures all greater than 0.7 , thus indicating a "middling" to

234 "meritorious" classification according to Kaiser (1974). Bartlett's test of sphericity was

235 statistically significant $(\mathrm{P}<0.0005)$, indicating that the data were suitable for factor analysis. Our

236 PCA identified two components with eigenvalues greater than 1, and which explained $42.1 \%$ and

$2378.5 \%$ of the total variance. Eigenvalues, visual inspection of Cattell's scree plot, interpretability

238 criteria and Cronbach's alpha value indicated that one component should be retained. A single-

239 component solution explained $42.1 \%$ of the total variance. Total score was obtained by summing

240 all items. Factor loadings of the rotated component solution for all 14 items of the WEMWBS

241 based on eigenvalues greater than 1 are shown in Table 3. The scree plot is illustrated in Figure 2422.

243 For interested readers, the results of exploratory factor analysis with the principal axis

244 factoring method are provided as supplementary file Table S1.

246 Internal consistency and content validity

247 The WEMWBS consists of 14 items. Cronbach's alpha for single-factor structure of the

248 WEMWBS was 0.89 . Corrected item correlations for all items were greater than 0.3 , thus

249 denoting the same construct for all items. Item-total statistics for all items are summarized in

250 Table 4. To further analyze internal consistency, we calculated item-total score correlations for

251 each item, with adjustment for overlap. These correlations ranged between 0.46 and 0.68 , which

252 are substantial but not excessive values. The item-total statistics for all items in the WEMWBS

253 are shown in Table 4. 


\section{$\underline{\text { Test-retest reliability }}$}

256 The test-retest reliability evaluated as the intraclass correlation coefficient was 0.921 , with a $95 \%$

257 confidence interval of $0.861-0.955$, thus indicating a very high degree of reliability.

258

259 Readability

260 The values for Flesch reading ease and FK grade level score were calculated in Microsoft Word 2013. Flesch reading ease score for the WEMWBS was 73.5, and FK grade level score was 4.4, which indicate that the WEMWBS was easy for our participants to read and understand.

\section{Discussion}

The present study confirms that in our sample of Pakistani HCPs, the WEMWBS showed reliability in measuring variations in a single-factor, high internal consistency, good validity and high readability. Our findings also indicate no floor or ceiling effects in the response distribution in our study population. Our sample was relatively large and consisted of a diverse range of health care professionals (physicians, surgeons, general practitioners, nurses, pharmacists, dentists and physiotherapists), which is an important strength of this study. obtained in general population surveys in the UK. The Health Survey for England identified a mean WEMWBS score for adults of 52.3 [30], and the mean score in a recent population survey in Scotland was 50.0 [31]. The median score in our study sample was 48, compared to 51 in the initial validation study [22] and 50 in a large-scale population sample in Northern Ireland [32]. 
We identified gender differences in well-being scores, as well as some differences

277

278

280

281

282

between professions and age groups. In this study, male HCPs scored higher on the WEMWBS than females, which is consistent with the findings of UK population studies [30,31].

Items 3, 4 and 5 were the least strongly endorsed by HCPs in our study. According to Taggart et al. (2013), item 4 ("I've been feeling interested in other people") was misinterpreted by Chinese and Pakistani groups in the UK, for whom it implied a sexual context [25]. This may be a potential reason for the less positive response to this item in our study.

Like other studies conducted in the general population of the UK, our analysis confirmed the unidimensional construct of the WEMWBS and high internal consistency [22,24]. However, the factor structure was not as clear-cut as in the original validation study [22] and other analyses, with some suggestion of two factors. However, the extent of cross-loading and the modest additional variance explained by two factors/components, together with the lack of explanatory or theoretical underpinning for this structure, indicate that a unidimensional model can be assumed.

A study of Pakistani people in the UK also showed high internal consistency, but as in the current study, the factor structure was less clear given that three factors were evident. Nevertheless, the limited variance explained by the second and third factors support a singlefactor model. [25]

There was some correspondence between the item-total correlations identified in our study and in the Taggart et al. study of UK English-speaking Pakistanis [25]. The three items with the lowest item-total correlations in our study (item 1, "I’ve been feeling optimistic about the future"; item 4, "I've been feeling interested in other people"; and item 5, "I've had energy to spare") also had the lowest correlations in the UK-Pakistani study, though the markedly low 
value for item 1 found in the UK sample (0.28) was not evident in our sample of Pakistani HCPs (0.488). In focus groups conducted as part of the UK study it was found that a quarter of Pakistanis who completed the questionnaire were native Pashtun speakers who were born abroad, and there is no translation for "optimistic" in the Pashto language [25]. However, our sample consisted of Punjabi- and Urdu-speaking health care professionals.

The histogram was slightly negatively skewed and kurtotic; however, no floor or ceiling effects were observed in the WEMWBS, in consonance with other validation studies. The WEMWBS may also prove useful for evaluating mental well-being in undergraduates thanks to its easy readability and lucid content, as demonstrated by its Flesch reading ease score and FK grade level score of 4.4. This fact was also supported by favorable comments from the participants in our pilot survey. Based on these findings, we speculate that this scale can be easily used for teenagers, college and university students.

\section{Limitations}

This cross-sectional study used a convenience sample of HCPs and so, unlike studies that involve a systematically derived probability sample, the extent to which the respondents are representative of the target population is uncertain. This is likely to be of less importance for psychometric evaluation than the descriptive results, and is partially compensated for by the relatively large sample size and high response rate: $91 \%$ of those asked to complete the questionnaire did so, which reduced participation and selection bias.

Comparator instruments were not used alongside the WEMWBS, so further efforts to evaluate criterion validity are advisable. 

language of Pakistan) were not done as part of this study, because our sample consisted of HCPs who were all capable of reading and writing in English. So although the WEMWBS has been

324 shown suitable for assessing mental well-being in a diverse group of HCPs, it cannot yet be used

325 for studies within the general population of Pakistan, where the extent of fluency in English is 326 considerably less.

The WEMWBS assesses hedonic and eudaimonic constructs of mental well-being but does not contain any items intended to evaluate in individual's spiritual and religious well-being - aspects which predominate in Eastern traditions and in Pakistani culture, where religious beliefs and attitudes have emerged as an important coping mechanism [33,34]. This potential limitation was also brought to light in a study of ethnic minority groups of Malay, Chinese and Indian Muslim and Hindu origin [35]. We therefore suggest that the new generation of psychometric instruments should include items designed to evaluate these constructs.

\section{Recommendations:}

336 The WEMWBS is particularly useful for monitoring mental well-being levels in HCPs and medical students who work in highly demanding roles and environments. Further studies are required to develop and validate an Urdu version of this scale in the general community. Along with general studies of the range of factors that are associated with mental health and well-being, the WEMWBS may also be useful to evaluate the efficacy of stress reduction programs such as mindfulness programs, relaxation exercises, cognitive therapies, and social support and group therapies which have proved useful in academic and hospital-based settings [36]. 


\section{Conclusion}

As far as we are aware, this is the first study designed to validate a scale used to evaluate mental well-being in a Pakistani sample, and is thus an important addition to the limited arsenal of validated psychometric instruments available for this population. The WEMWBS showed excellent psychometric properties in Pakistani HCPs, and appears to be a valid and reliable tool for use among English-speaking Pakistani people.

\section{Acknowledgements}

The authors thank Professor Dr. Atif Rahman, Professor of Child Psychiatry at the University of Liverpool, United Kingdom, for his valuable suggestions for improving this manuscript. The authors also thank K. Shashok (AuthorAid in the Eastern Mediterranean) for improving the use of English in the manuscript.

\section{References}

Official Records of the World Health Organization. Preamble to the Constitution of the World Health Organization as adopted by the International Health Conference, New York, 19-22 June, 1946; signed on 22 July 1946 by the representatives of 61 States and entered into force on 7 April 1948. 1946.

World Health Organisation. WHO: Promoting Mental Health: Concepts, Emerging Evidence, Practice. Geneva. 2004.

OECD. OECD Guidelines on Measuring SubjectiveWell-being. 2013. doi:http://dx.doi.org/10.1787/9789264191655-en World Health Organization, Regional Office for Europe, Psychiatric Research Unit. WHO-5 well-being index (WHO, 1998 World Health Organization info package: Mastering depression in primary care. Frederiksborg. 1998. McHorney C, Ware JJ, Lu J, Sherbourne C. The MOS 36-item Short-Form Health Survey (SF36): III. Tests of data quality, scaling assumptions, and reliability across diverse patient groups. Med care. 1994;32: 40-66. 
6.74 Eurofound. European quality of life survey [Internet]. 2012 [cited 12 Jun 2015]. Available:

375 http://www.eurofound.europa.eu/surveys/european-quality-of-life-surveys-eqls/european-

376 quality-of-life-survey-2012

3.77 Stiglitz J, Sen A, Fitoussi J. Report by the Commission on the Measurement of Economic

378 Performance and Social Progress. 2009.

8.79 Slade M. Mental illness and well-being: the central importance of positive psychology and

380 recovery approaches. BMC Heal Serv Res. 2010;10: 26.

981 Warner R. Recovery from schizophrenia and the recovery model. Curr Opin Psychiatry. 2009;

382 374-80. doi:10.1097/YCO.0b013e32832c920b

B83 Nolte E, McKee M. Caring for people with chronic conditions. A health system perspective.

384 World Health Organization 2008 on behalf of the European Observatory on Health Systems and

385 Policies. Maidenhead: OUP [Internet]. 2008. Available:

386 http://www.euro.who.int/_data/assets/pdf_file/0006/96468/E91878.pdf

B87. Royal College of Physicians. Work and wellbeing in the NHS: why staff health matters to patient

388 care [Internet]. 2015. Available:

389 https://www.rcplondon.ac.uk/sites/default/files/comms_wwnhs_a4_12pp_final.pdf

B20 Boorman S. NHS health and wellbeing review: interim report. London: Department of Health.

3912009.

B92 Eurofound. Fifth European Working Conditions Survey. [Internet]. 2012. Available:

393 www.eurofound.europa.eu/publications/htmlfiles/ef1 182.htm. Luxembourg

B94 Health and safety executive. Stress-related and psychological disorders in Great Britain 2014

395 [Internet]. 2015. Available: http://www.hse.gov.uk/statistics/causdis/stress/

B96 McManus C. Stress in Health Professionals. [Internet]. Ayers et al., editor. Cambridge Handbook

397 of Psychology, Health and Medicine. Cambridge: CUP; Available:

398 http://www.ucl.ac.uk/medical-education/reprints/2007-StressInHealthProfessionals-

399 CambridgeHandbook.pdf

\#60 Waqas A, Khan S, Sharif W, Khalid U, Ali A. Association of academic stress with sleeping

401 difficulties in medical students of a Pakistani medical school: a cross sectional survey. PeerJ.

402 2015;3: e840. doi:10.7717/peerj.840

\$ఐ3 Prins J, Gazendam-Donofrio S, Tubben B, van der Heijden F, van de Wiel H, Hoekstra-Weebers

404 J. Burnout in medical residents: a review. Med Ed. 2007;41: 788-800.

485 Aslam HD, Mansoor N, Suleman Q. Analysis of Level of Stress among Doctors in Public and

406 Private Hospitals of Pakistan. Int J Learn Dev. 2013;3: 109-135. doi:10.5296/ijld.v3i2.6247

$\$ 9.7$ Usman R, Nafees F, Farooqui SI, Faruq NM. Level of satisfaction of physiotherapists with

408 regards to their profession. Pakistan J Rehabil. 2013;2: 41-47.

209 Fradelos E, Mpelegrinos S, Mparo C, Vassilopoulou C, Argyrou P, Tsironi M, Zyga S, Theofilou

410 P. Burnout syndrome impacts on quality of life in nursing professionals : The contribution of

411 perceived social support. Prog Heal Sci. 2014;4: 102-109.

212 Ahmer S, Faruqui RA, Aijaz A. Psychiatric rating scales in Urdu: a systematic review. BMC

413 Psychiatry. 2007;7: 59. doi:10.1186/1471-244X-7-59

224 Tennant R, Hiller L, Fishwick R, Platt S, Joseph S, Weich S, Parkinson J, Secker J, Stewart-

415 Brown S. et al. The Warwick-Edinburgh Mental Well-being Scale (WEMWBS): development

416 and UK validation. Health Qual Life Outcomes. 2007;5: 63. doi:10.1186/1477-7525-5-63

23.7 Castellví P, Forero C, Codony M, Vilagut G, Brugulat P, Medina A, Gabilondo A, Mompart A,

418 Colom J, Tresserras R et al. The Spanish version of the Warwick-Edinburgh mental well-being

419 scale (WEMWBS) is valid for use in the general population. Qual Life Res. 2014;23: 857-68. 
Clarke A, Friede T, Putz R, Ashdown J, Martin S, Blake A, Adi Y, Parkinson J, Flynn P, Platt S, et al. Warwick-Edinburgh Mental Well-being Scale (WEMWBS): validated for teenage school students in England and Scotland. A mixed methods assessment. BMC Public Health. BioMed Central Ltd; 2011;11: 487. doi:10.1186/1471-2458-11-487

Taggart F, Friede T, Weich S, Clarke A, Johnson M, Stewart-Brown S. Cross cultural evaluation of the Warwick-Edinburgh mental well-being scale (WEMWBS) -a mixed methods study. Health Qual Life Outcomes. Health and Quality of Life Outcomes; 2013;11: 27. doi:10.1186/1477-7525-11-27

MacCallum R, Widaman K, Zhang S, Hong S. Sample size in factor analysis. Psychol Methods. 1999;4.

Comrey AL, Lee H. A first course in factor analysis. Hillsdale, NJ: Erlbaum. 1992.

Streiner D. Health measurement scales: a practical guide to their development and use. 4th ed. Oxford University Press; 2008.

Flesch R. A new readability yardstick. J Appl Psychol. 1948;32: 221-33.

Bridges S. Health Survey for England, 2012. The Health and Social Care Information Centre. [Internet]. 2013. Available: http://www.hscic.gov.uk/catalogue/PUB13218/HSE2012-Ch5Wellbeing.pdf

Wilson, Kellock C, Adams D, Landsberg J. The Scottish Health Survey: Topic Report -Mental Health and Wellbeing. Published by The Scottish Government. [Internet]. 2015. Available: http://www.gov.scot/Resource/0046/00469088.pdf

Lloyd K, Devine P. Psychometric properties of the Warwick-Edinburgh mental well-being scale (WEMWBS) in Northern Ireland. J Ment Heal. 2012;21: 257-263.

Waqas A, Zubair M, Ghulam H, Wajih Ullah M, Zubair Tariq M. Public stigma associated with mental illnesses in Pakistani university students: a cross sectional survey. PeerJ. 2014;2: e698. doi: $10.7717 /$ peerj. 698

Voll JO. Conservative and Traditional Brotherhoods. Ann Am Acad Polit Soc Sci. 1992;524: 66-78.

Vaingankar J, Subramaniam M, Chong S, Abdin E, Orlando E, Picco L, Lim YW, Phua MY, Chua BY, Tee JY, et al. The positive mental health instrument: development and validation of a culturally relevant scale in a multi-ethnic Asian population. Health Qual Life Outcomes. 2011;9: $1-18$.

Shapiro SL, Shapiro DE, Schwartz GE. Stress management in medical education: a review of the literature. Acad Med. 2000;75: 748-59. Available:

http://www.ncbi.nlm.nih.gov/pubmed/10926029 
468

469

470

471

472

473

474

475

476

477

478

479

480

481

482

483

484

485

486

487

488

489 
Table $\mathbf{1}$ (on next page)

Demographic characteristics of a sample of 1271 health care providers in Punjab province, Pakistan, who completed the Warwick-Edinburgh Mental Well-being Scale (WEMWBS) 
1 Table 1. Demographic characteristics of a sample of 1271 health care providers in Punjab 2 province, Pakistan, who completed the Warwick-Edinburgh Mental Well-being Scale

3 (WEMWBS) between June 2013 and December 2014

\begin{tabular}{|l|l|l|l|}
\hline \multicolumn{2}{|l|}{ Variable } & Frequency (n) & $\begin{array}{l}\text { WEMWBS } \\
\text { Mean (SD) }\end{array}$ \\
\hline Gender & Male & $551(43.4 \%)$ & $49.16(9.16)$ \\
\hline & Female & $720(56.6 \%)$ & $47.30(9.59)$ \\
\hline Healthcare Profession & Doctor & $840(66.1 \%)$ & $47.74(9.57)$ \\
\hline & Nurse & $218(17.2 \%)$ & $47.74(9.45)$ \\
\hline & Pharmacist & $53(4.2 \%)$ & $50.28(8.35)$ \\
\hline & Physiotherapist & $25(2 \%)$ & $49.44(6.90)$ \\
\hline City & Dentist & $135(10.6 \%)$ & $49.93(9.26)$ \\
\hline & Lahore & $893(70.3 \%)$ & \\
\hline & Multan & $86(6.8 \%)$ & \\
\hline & Sheikhupura & $54(4.2 \%)$ & \\
\hline & Gujrat & $58(4.6 \%)$ & \\
\hline & Rawalpindi & $101(7.9 \%)$ & \\
\hline & Faisalabad & $54(4.2 \%)$ & \\
\hline Age & Islamabad & $25(2 \%)$ & \\
\hline & $>=30$ & $542(42.6 \%)$ & $48.87(9.11)$ \\
\hline & $<30$ & $729(57.4 \%)$ & $47.54(9.65)$ \\
\hline
\end{tabular}


Table 2 (on next page)

Item-level statistics for responses on the Warwick-Edinburgh Mental Well-being Scale in a sample of Pakistani health care providers $(n=1271)$ 
1 Table 2. Item-level statistics for responses on the Warwick-Edinburgh Mental Well-being

2 Scale in a sample of Pakistani health care providers $(n=1271)$

\begin{tabular}{|l|r|r|}
\hline Statement & Mean & Std. Deviation \\
\hline I've been feeling optimistic about the future & 3.36 & 1.109 \\
\hline I've been feeling useful & 3.74 & .991 \\
\hline I've been feeling relaxed & 3.03 & 1.085 \\
\hline I've been feeling interested in other people & 2.97 & 1.140 \\
\hline I've had energy to spare & 2.88 & 1.113 \\
\hline I've been dealing with problems well & 3.53 & .959 \\
\hline I've been thinking clearly & 3.59 & 1.034 \\
\hline I've been feeling good about myself & 3.58 & 1.052 \\
\hline I've been feeling close to other people & 3.33 & 1.053 \\
\hline I've been feeling confident & 3.74 & .999 \\
\hline I've been able to make up my own mind about things & 3.72 & .992 \\
\hline I've been feeling loved & 3.64 & 1.038 \\
\hline I've been interested in new things & 3.58 & 1.111 \\
\hline I've been feeling cheerful & 3.42 & 1.022 \\
\hline
\end{tabular}

3 
Table 3 (on next page)

Factor loadings for the 14 items in the Warwick-Edinburgh Mental Well-being Scale in a sample of Pakistani health care providers $(n=1271)$ 
Table 3. Factor loadings for the 14 items in the Warwick-Edinburgh Mental Well-being Scale in a sample of Pakistani health care providers $(n=1271)$

\begin{tabular}{|l|c|c|}
\hline \multicolumn{1}{|c|}{ Statements } & \multicolumn{2}{c|}{ Factor Loading } \\
\cline { 2 - 3 } & I & II \\
\hline I've been feeling confident (Item 10) & .789 & \\
\hline I've been feeling good about myself (Item 8) & .776 & \\
\hline I've been thinking clearly (Item 7) & .744 & \\
\hline I've been able to make up my own mind about things (Item 11) & .722 & \\
\hline I've been dealing with problems well (Item 6) & .703 & \\
\hline I've been feeling cheerful (Item 14) & .686 & \\
\hline I've been feeling close to other people (Item 9) & .670 & \\
\hline I've been feeling useful (Item 2) & .637 & \\
\hline I've been feeling loved (Item 12) & .625 & \\
\hline I've been interested in new things (Item 13) & .578 & \\
\hline I've been feeling optimistic about the future (Item 1) & .541 & \\
\hline I've been feeling interested in other people (Item 4) & .390 & .663 \\
\hline I've had energy to spare (Item 5) & .378 & .646 \\
\hline I've been feeling relaxed (Item 3) & .508 & .528 \\
\hline
\end{tabular}

Extraction Method: Principal Component Analysis.

Rotation Method: Quartimax with Kaiser Normalization.

Rotation converged in 3 iterations. 


\section{Table 4(on next page)}

Item-total statistics for the 14 items in the Warwick-Edinburgh Mental Well-being Scale in a sample of Pakistani health care providers $(n=1271)$ 
Table 4. Item-total statistics for the 14 items in the Warwick-Edinburgh Mental Well-being Scale in a sample of Pakistani health care providers $(n=1271)$

\begin{tabular}{|l|r|r|r|r|r|}
\hline & $\begin{array}{r}\text { Scale Mean if } \\
\text { Item Deleted }\end{array}$ & $\begin{array}{c}\text { Scale } \\
\text { Variance if } \\
\text { Item Deleted }\end{array}$ & $\begin{array}{c}\text { Corrected } \\
\text { Item-Total } \\
\text { Correlation }\end{array}$ & $\begin{array}{c}\text { Squared } \\
\text { Multiple } \\
\text { Correlation }\end{array}$ & $\begin{array}{c}\text { Cronbach's } \\
\text { Alpha if Item } \\
\text { Deleted }\end{array}$ \\
\hline $\begin{array}{l}\text { I've been feeling } \\
\text { optimistic about the } \\
\text { future }\end{array}$ & 44.75 & 78.422 & .488 & .293 & .887 \\
\hline I've been feeling useful & 44.37 & 78.627 & .548 & .350 & .884 \\
\hline $\begin{array}{l}\text { I've been feeling } \\
\text { relaxed }\end{array}$ & 45.08 & 77.650 & .544 & .355 & .884 \\
\hline $\begin{array}{l}\text { I've been feeling } \\
\text { interested in other } \\
\text { people }\end{array}$ & 45.13 & 78.590 & .462 & .292 & .888 \\
\hline $\begin{array}{l}\text { I've had energy to spare } \\
\text { I've been dealing with } \\
\text { problems well }\end{array}$ & 45.23 & 79.177 & .445 & .289 & .889 \\
\hline $\begin{array}{l}\text { I've been thinking } \\
\text { clearly }\end{array}$ & 44.58 & 77.894 & .616 & .447 & .881 \\
\hline $\begin{array}{l}\text { I've been feeling good } \\
\text { about myself }\end{array}$ & 44.52 & 76.722 & .631 & .490 & .880 \\
\hline $\begin{array}{l}\text { I've been feeling close } \\
\text { to other people }\end{array}$ & 44.78 & 76.788 & .614 & .424 & .878 \\
\hline $\begin{array}{l}\text { I've been feeling } \\
\text { confident }\end{array}$ & 44.37 & 76.938 & .644 & .518 & .881 \\
\hline $\begin{array}{l}\text { I've been able to make } \\
\text { up my own mind about } \\
\text { things }\end{array}$ & 44.39 & 77.959 & .587 & .421 & .880 \\
\hline I've been feeling loved & 44.47 & 78.118 & .547 & .348 & .889 \\
\hline $\begin{array}{l}\text { I've been interested in } \\
\text { new things }\end{array}$ & 44.52 & 77.251 & .550 & .352 & .882 \\
\hline $\begin{array}{l}\text { I've been feeling } \\
\text { cheerful }\end{array}$ & 44.69 & 76.463 & .656 & .492 & .879 \\
\hline
\end{tabular}


1

Frequency distribution of total scores of Pakistani HCPs on WEMWBS $(n=1271)$

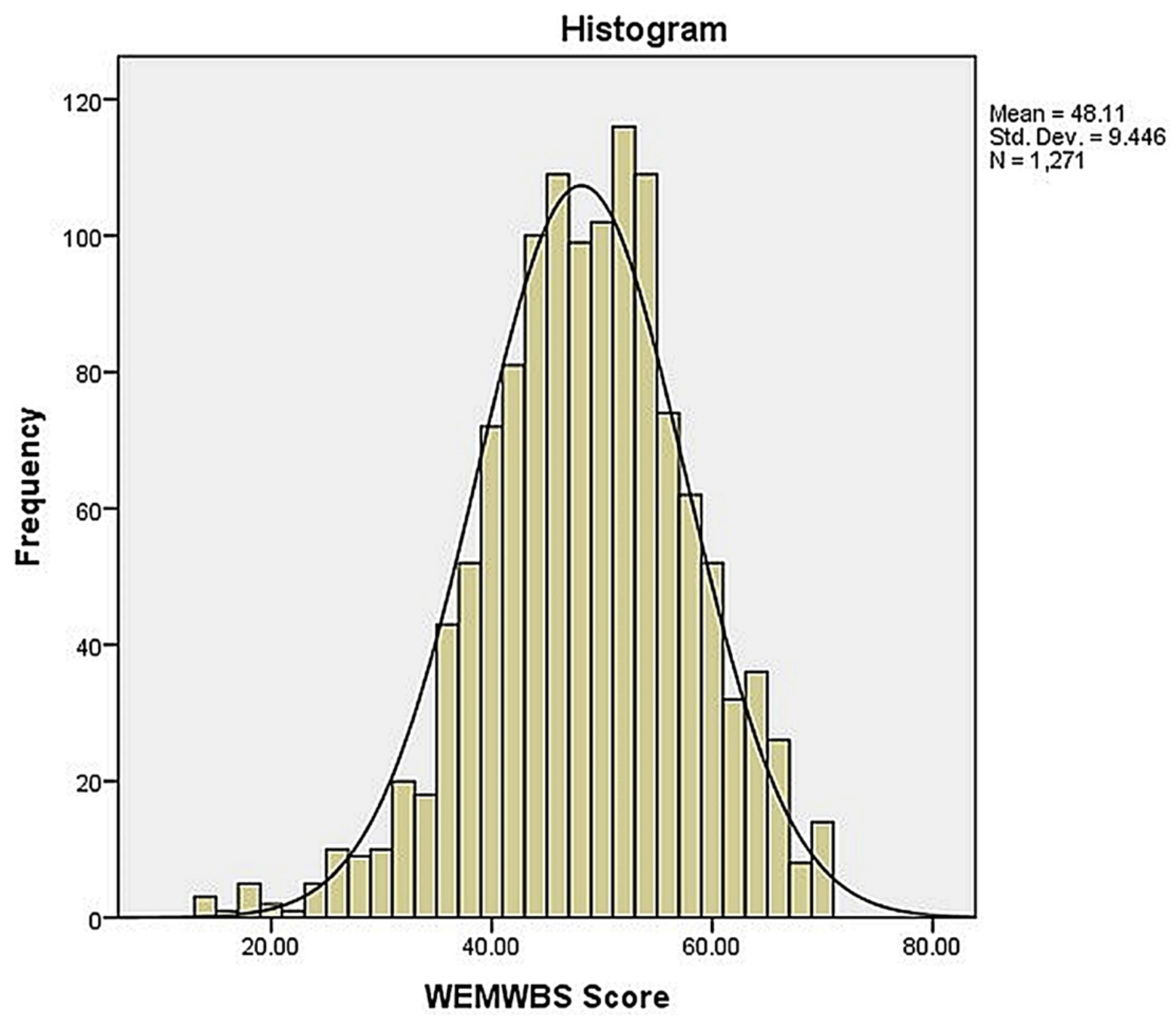


2

Scree plot for 14-item WEMWBS

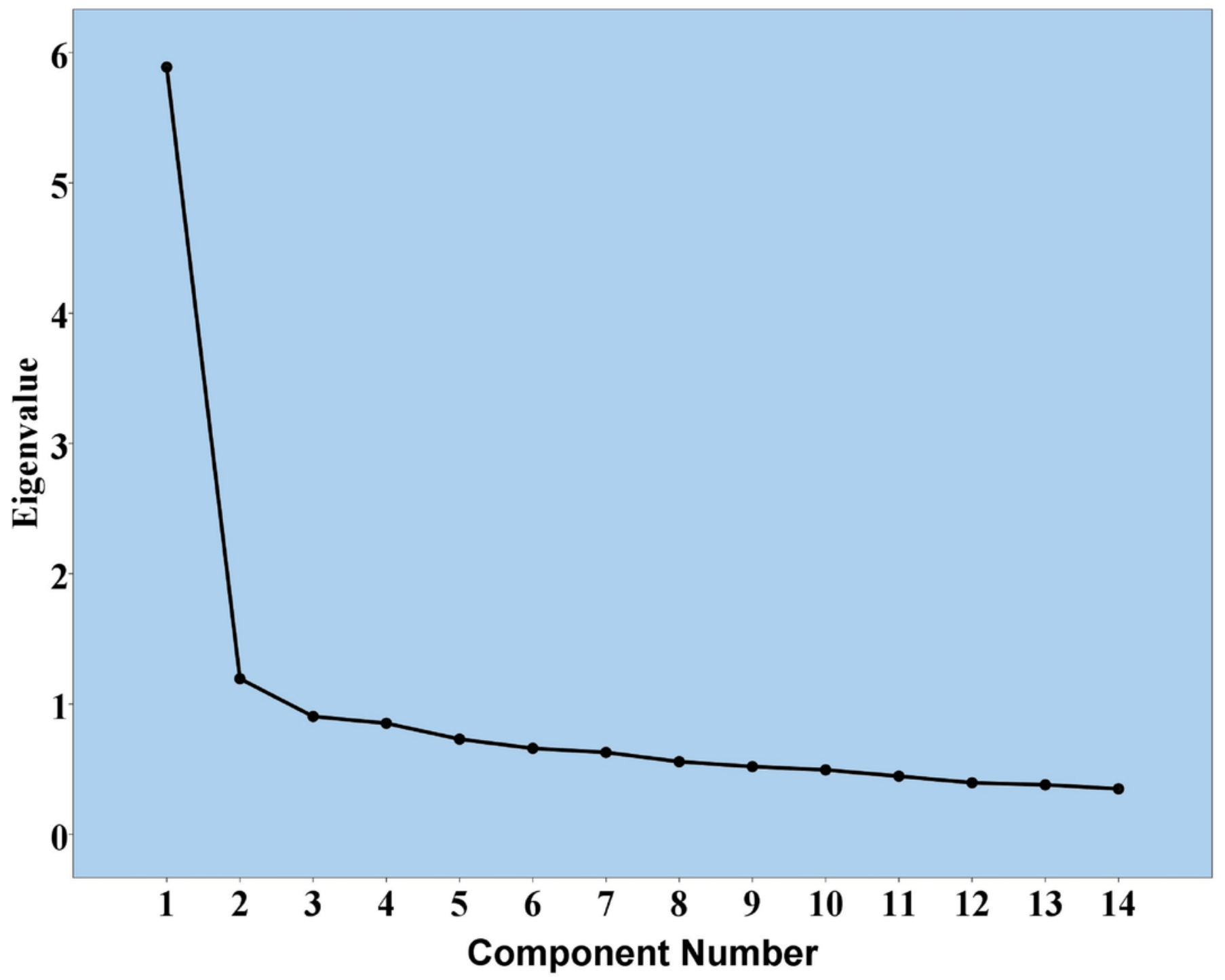

